\title{
Pre-purification by membrane filtration of paralytic shellfish toxins from Alexandrium minutum dinoflagellate
}

\author{
Balti Rafik ${ }^{1,2}$, Brodu Nicolas ${ }^{1,3}$, Zhang Jiaxuan ${ }^{1}$, Amzil Zouher ${ }^{4}$, Drouin Delphine ${ }^{1}$, \\ Séchet Veronique ${ }^{4}$, Massé Anthony ${ }^{1, *}$
}

${ }^{1}$ LUNAM, Université de Nantes, GEPEA, UMR-CNRS 6144, 37 Bd Université, BP 406, 44602 SaintNazaire Cédex, France

${ }^{2}$ Unité de Physiologie Fonctionnelle et Valorisation des Bio-Ressources (UR17ES27), Higher Institute

of Biotechnology of Beja, University of Jendouba, PB 382, Habib Bourguiba Avenue, 9000 Beja, Tunisia

${ }^{3}$ NormandieUniv, UNIROUEN, INSA Rouen, LSPC, 76000 Rouen, France

${ }^{4}$ Ifremer, Laboratoire Phycotoxines, Centre de Nantes, BP 21105, 44311, Nantes, France

* Corresponding author : Anthony Massé, email address : Anthony.masse@univ-nantes.fr

\begin{abstract}
:
The Paralytic shellfish neurotoxins (PST) are of increasing interest for biomedical applications. The chemical synthesis is often complex and expensive that's why the purification by membrane filtration of PST from Alexandrium minutum dinoflagellate was investigated. Disrupted micro-alga cells by ultrasonic treatment were diafiltred to let pass toxins through an ultrafiltration membrane. Then, the mean permeate was concentrated and diafiltrated by nanofiltration. Mean permeate fluxes equal to 187,135 and 135 L.h-1.m-2 were obtained during the first diafiltration, the concentration step and the final diafiltration respectively. Up to $57 \%(\mathrm{~mol} / \mathrm{mol})$ and $78 \%(\mathrm{~mol} / \mathrm{mol})$ of organic matters and salts were removed respectively. Divalent ions were sparsely removed contrary to monovalent ones. C1 and C2 toxins were successfully purified since more than $75 \%(\mathrm{~mol} / \mathrm{mol})$ were recovered. However, only 27 to $50 \%(\mathrm{~mol} / \mathrm{mol})$ of GTX2, GTX3 and STX were recovered.
\end{abstract}

\section{Highlights}

Mean permeate fluxes ranged from 135 to $187 \mathrm{~L} \cdot \mathrm{h}^{-1} \cdot \mathrm{m}^{-2}$ for the complete sequence of filtrations. Divalent ions were sparsely removed contrary to monovalent ones. Up to $57 \%$ and $78 \%(\mathrm{~mol} / \mathrm{mol})$ of organic matters and salts were removed respectively. More than $75 \%(\mathrm{~mol} / \mathrm{mol})$ of $\mathrm{C} 1$ and $\mathrm{C} 2$ were recovered, only 27 to $50 \%$ for GTX2, GTX3 and STX. Biggest toxins (C1 and C2) were pre-purified contrary to GTX2, GTX3 and STX.

Keywords : Paralytic shellfish poisoning, nanofiltration, membrane, Alexandrium minutum, purification 


\section{Introduction}

In the world's oceans, among the 27,000 kinds of marine microalgae 50 species can produce potent toxins (Rossini 2014). Every year, many of these toxins are responsible for severe illness or death, mostly related to consumption of seafood contaminated by toxic algae. Toxins from algae represent a major threat for human and animal health and cause several disorders of the immune system as well as immunological, reproductive, neurological, etc.

Thus, the extraction and purification of these bioactive compounds, notably neurotoxins, are of increasing interest for medicine, biomedical and pharmacological applications and researches. For instance, the production of Paralytic shellfish neurotoxin standards (PSTs) is needed for seafood and water monitoring programs and instrument calibration (Hejazi and Wijffels 2004, Camacho et al. 2007). PSTs can also be used for studies dealing with the change of sodium ion transport in cell membrane channels as well as for the treatment of chronic tension type headaches or anal fissures as anesthetic (Wang 2008, Lattes et al. 2009, Garridoet al. 2007). In addition, prices of PST toxins can reach 30,000 euros per milligram (Gallardo-Rodriguez et al. 2012). Nevertheless, high amounts (around $150 \mathrm{~g}$ ) of pure compounds can be needed, notably for preclinical and clinical trials (Gallardo-Rodriguez et al. 2012).

Most PSTs are non-proteinaceous water-soluble alkaloids with molecular weights ranged from 256 to 491 g.mol ${ }^{-1}$ (Coral et al., 2011, Wang 2008). For instance, molar masses of STX, GTX2, GTX3, C1 and C2 are equal to 299, 395, 395, 475 and $475 \mathrm{Da}$, respectively. These molecules have usually hydrophobic and hydrophilic parts. All PSTs have a similar structure but varied by their substituent R1-R4 (Table 1 ). $\mathrm{R}_{1}$ may be hydroxylated or non-hydroxylated. A sulfate group may be present on $\mathrm{R}_{2}$ or $\mathrm{R}_{3}$ but not both. $\mathrm{R}_{4}$ shows most variation and may have carbamate (STX, NSTX, GTX), N-sulfocarbamoyl (C and B) and decarbamoyl groups (dcSTX, dcGTX, dcNSTX). PSTs are tricyclic molecules with two guanidine groups having $\mathrm{pK}_{\mathrm{a}}$ values of 8.2 and 11.3 (Rogers et al. 1980).

A chemical synthesis of toxins can be considered but it is often complex and expensive (Inoue, 2004). Recently, the cultivation of Dinoflagellates in bioreactors seems more suitable alternative for the large scale production of toxins (Gallardo-Rodriguez et al. 2012). Nevertheless, the recovery and purification of PSTs are a key issue. Toxins can be located in the cell cytoplasm or walls as well as released into the medium. Thus, cell breakage, by freezing-thawing, addition of alcohol or detergent, bead milling, etc. is often carried out before recovery (Haque et al. 2017). Extraction of neurotoxins can be obtained by aqueous two-phase systems, notably an aqueous phase with a high salt concentration and a polymer- 
containing phase (Hejazi and Wijffels 2004). Methanol and water can also be used as solvent as well as supercritical fluids (Haque et al. 2017, Pyo et al. 2004). Neurotoxins such as saxitoxins can also be adsorbed on powder activated carbon (Ho et al. 2009, Westrick et al. 2010, Buarque et al. 2015). Nevertheless, the desorption can be difficult without molecule damage. Toxins can also be separated by liquid chromatography, with a reversed phase C18 or a hydrophilic interaction liquid chromatography column and methanol/water or water/acetonitrile as a mobile phase (Merel et al. 2013). Nevertheless, this technique is more often used for analytical purpose. Moreover, the toxin separation from the solvent will be needed for certain applications. The membrane process could be an interesting way for PST recovery and purification. Molecules larger than a hundred Dalton can be retained, at least partially, by nanofiltration or reverse osmosis. This technology is interesting for the recovery of natural sensitive compounds and for the volume reduction at large scale. Moreover, no chemical addition is needed. Several works focused on anatoxin-a, mycrocystins or cylindrospermopsin membrane recovery but few studies on the PSTs (Teixeira and Rosa 2006, Gijsbertsen-Abrahamse et al. 2006, Dixon et al. 2011, Vlad et al. 2014). In addition to toxin molecular weight, several parameters such as membrane material, operating conditions, toxin charge and hydrophobicity, etc. affect the membrane rejection rates and hydraulic performances. The toxin retention yields would be $\mathrm{pH}$ and ionic composition dependent (Alvarez et al. 2010). Some hydrophobic interactions can also occur between the membrane and the toxins (Teixeira and Rosa 2005). Water quality and the content of natural organic matter can also have a strong influence on the toxin transmission through the membrane. It should be noted that an efficient removal of saxitoxins (greater than 99\%) was obtained during the filtration by reverse osmosis of a solution containing $512 \mu \mathrm{g} . \mathrm{L}^{-1}$ and $32 \mathrm{~g} . \mathrm{L}^{-1}$ of toxins and salts respectively (Laycock et al. 2012). Other study mentioned complete saxitoxin retention during the reverse osmosis of $2 \mu \mathrm{g} . \mathrm{L}^{-1}$ salted solutions (Seubert et al. 2012). Nevertheless, the retention rates reported into the literature are sometimes obtained from filtrations of water with low toxin concentrations. Higher concentrations of toxins could induce a passage of these biomolecules through the membranes. Moreover, the nanofiltration could advantageously replace the reverse osmosis. Indeed, the permeate fluxes could be better inducing a shorter time of purification. Nevertheless, in that case, it is necessary to ensure that retention of toxins was still good. So, this work deals with the feasibility to purify the Alexandrium minutum's PST by a sequence of membrane process.

\section{Material and methods}




\subsection{Microalga cultivation and cells disruption}

Alexandrium minutum (AM89BM and AM99PZ strain) was grown in 100-liter bioreactor fed by filtered natural seawater enriched with L1 medium (Guillard and Hargraves 1993). The salinity of the culture was equal to $35 \mathrm{psu}$ (Practical Salinity Unit, $1 \mathrm{psu} \approx 1 \mathrm{~g} / \mathrm{kg}$ ) and $\mathrm{pH}$ regulated at 8.0. After 16 days/8 nights photoperiod with irradiance equal to $200 \mu$ mole. $\mathrm{m}^{-2} \cdot \mathrm{s}^{-}$ ${ }^{1}$, the culture was centrifuged at $4300 \mathrm{~g}$ for 20 minutes at $4^{\circ} \mathrm{C}$. Then, cell pellets were collected, dissolved in $0.1 \mathrm{~N}$ acetic acid and disrupted by ultrasonic probe with $10 \mathrm{~s}$ pulses during 20 minutes. Then deionized water was added in order to obtain $1.9 \mathrm{~L}$ of toxin solution. This volume made it possible to completely fill the pilot-plant and perform the filtration.

\subsection{Steps of toxins purification with membrane process}

Disrupted micro-algal cells were firstly diafiltred. Toxins should pass through the ultrafiltration membrane while particles and various colloids would be retained. Then all the volume of mean permeate obtained previously was reduced by nanofiltration before being diafiltred again in order to remove salts and small undesirable organics. The mean permeate refers to the entire permeate collected at the end of the filtration. The volume reduction step and the last diafiltration were consecutively performed with the same nanofiltration membrane. All diafiltrations were carried out with deionized water (Figure 1).

During the diafiltration steps, the concentration of compounds within the retentate $\left(C_{R}\right.$ or $C_{R 0}$ for the initial concentration) was determined. These concentrations are linked to the retention rate (R) and the number of diavolume (DV) as Cheryan (1986) demonstrated it:

$$
C_{R}=C_{R 0} \cdot e^{-(1-R) \cdot D V} \quad \text { equation } 1
$$

The number of diavolume is defined as the ratio of the volume of water added to the feed tank $\left(\mathrm{V}_{\mathrm{W}}\right)$ and the initial volume of extract $\left(\mathrm{V}_{\mathrm{R} 0}\right)$. The mean retention rate $(\mathrm{R})$ is linked to the transmission rate $(\mathrm{Tr})$ as:

$$
\mathrm{R}=1-\operatorname{Tr}=\left(\mathrm{C}_{\mathrm{R}}-\mathrm{C}_{\mathrm{P}}\right) / \mathrm{C}_{\mathrm{R}} \quad \text { equation } 2
$$

where $C_{P}$ is the solute concentration in the permeate and $C_{R}$ is the solute concentration in the retentate.

Batch mode was also used for the volume reduction step. The volume reduction factor (VRF) is defined as the ratio of the initial feed volume $\left(\mathrm{V}_{\mathrm{R} 0}\right)$ and the retentate $\left(\mathrm{V}_{\mathrm{R}}\right)$ one: 
$\mathrm{VRF}=\mathrm{V}_{\mathrm{R} 0} / \mathrm{V}_{\mathrm{R}} \quad$ equation 3

\subsection{Design of the membrane filtration system}

A volumetric pump fed the membrane module (Figure 2). A part of the retentate was recirculated to the feed tank while the other part passed through a heat exchanger in order to maintain a temperature of filtration equal to $20^{\circ} \mathrm{C}$.

The first diafiltration was performed at 20 bar. The retentate volume (1.9 L) was kept constant during this step. The mean permeate $(7.8 \mathrm{~L})$ obtained at the previous step was then concentrated, at 35 bar, until $1.9 \mathrm{~L}$ was reached. Finally, the last diafiltration step was carried out at 35 bar. The retentate volume was kept constant again.

The transmembrane pressures chosen for the filtrations were in the range of those classically used for such membranes. They do not exceed the maximum pressure tolerated by the ultrafiltration (30 bar) and nanofiltration (60 bar) membrane following manufacturer recommendations (Table 2).

The pilot plant used for this study was equipped with tubular membranes from XYLEM PCI. The ultrafiltration (ESP04) or nanofiltration (AFC30) membranes had an active surface area of $0.033 \mathrm{~m}^{2}$. Some physical characteristics of both membranes are presented in Table 2 . Membranes were cleaned with circulation of Ultrasil53 - Ecolab $(10 \mathrm{~g} / \mathrm{L})$ at $50-55{ }^{\circ} \mathrm{C}$ in closed loop followed by the circulation of nitric acid $(2 \mathrm{~mL} / \mathrm{L})$ at $35 \circ \mathrm{C}$ both at 8 bars. Finally, Milli-Q® water was filtered at 8 bars until neutral $\mathrm{pH}$ of the permeate. More than $90 \%$ of the water fluxes were recovered after the cleaning procedure.

\subsection{Ion concentration measurement}

Ionic chromatography (DIONEX) was used to measure the ion concentration. It was composed of two units, cationic chromatography ICS-1100 and anionic chromatography ICS900. Each was associated with an ion exchange resin (stationary phase), one for the cations and the other for anions. Sulfuric acid with a concentration of $20 \mathrm{mM}$ was used as eluent for the ICS-1100. The mixture of sodium carbonate $(0.77 \mathrm{mM})$ and sodium bicarbonate $(0.13$ $\mathrm{mM}$ ) solutions was used as eluent (mobile phase) for ICS-900. Detection was carried out by conductivity and concentrations were determined using internal standards. Data were transferred to the computer with Chromeleon software Version 7.0. The samples were filtered 
to $0.45 \mu \mathrm{m}$ before measurement by ionic chromatography of $\mathrm{Cl}^{-}, \mathrm{SO}_{4}{ }^{2-}, \mathrm{Na}^{+}, \mathrm{K}^{+}, \mathrm{Mg}^{2+}$, and $\mathrm{Ca}^{2+}$ salts.

2.5. Total organic carbon analysis

Total organic carbon (TOC) was analyzed with Shimazu TOC-L. Samples were acidified with $2 \mathrm{~N} \mathrm{HCl}$, bubbled with air during 1 minute and 30 seconds directly into the injection syringe of the apparatus. Then, the samples were injected into a vertical furnace (tube filled with catalytic beads) and heated to $680^{\circ} \mathrm{C}$. Calibration curves were realized with saline solutions of hydrogen phthalate.

\subsection{PST measurements}

Analysis of PST toxins was performed by liquid chromatography and fluorescence detection (LC/FD) according to Oshimaet al. (1995) with slight modifications. Toxins were separated using reverse phase chromatography on a C8 column ( $5 \mu \mathrm{m}$ Develosil, $4.6 \mathrm{~mm}$ x $250 \mathrm{~mm})$ with a flow rate of $0.8 \mathrm{~mL} \cdot \mathrm{min}^{-1}$. Toxins were quantified using certified standards provided by CNRC-Halifax-Canada. B2 and C-toxins were detected and quantified indirectly following acid hydrolysis $\left(\mathrm{HCl} 0.4 \mathrm{~N}\right.$ at $97^{\circ} \mathrm{C}$ for a period of $5 \mathrm{~min}$ ). Analyses were performed 3 times for each sample.

\section{Results and discussion}

3.1. Mass balance at the inlet and outlet of each step of the purification chain All filtration steps were achieved after few minutes $(258 \mathrm{~min})$ thanks to rather good mean permeate fluxes equal to 187,135 and $135 \mathrm{~L} \cdot \mathrm{h}^{-1} \cdot \mathrm{m}^{-2}$ for respectively the EPS04-diafiltration, AFC30-concentration and AFC30-diafiltration (Table 3). At the end of the purification chain, the retentate volume was still equal to $1.9 \mathrm{~L}$. The final concentration of toxins could obviously be higher for higher volume reduction factors.

$\mathrm{C} 1$ toxins were the most found into the feedstock solution with a concentration equal to $1.8 \mu$ mol. $L^{-1}$ (Table 3). Trace amounts of dc-GTX2 $\left(0.05 \mu\right.$ mol. $\left.L^{-1}\right)$ and dc-GTX3 $0.01 \mu \mathrm{mol} . \mathrm{L}^{-1}$ ) were found. After the complete purification process, the $\mathrm{C} 1$ toxins were still the most abundant $\left(1.42 \mu \mathrm{mol} . \mathrm{L}^{-1}\right)$. Unfortunately, losses of some amounts of toxins occurred during the filtrations, whatever the type of toxins. Thus, only 27 to $77 \%$ (mol/mol) of toxins were recovered after the complete sequence of filtrations. $\mathrm{C} 1$ and $\mathrm{C} 2$ toxins were the most recovered with relatively high yields about 77 and $75 \%$, respectively (Table 3). 
Figure 3 shows the loss rates of toxins after each step of filtration. The loss rate is defined as the percentage of toxins which were not recovered into (i) the final mean permeate of the first diafiltration, (ii) the final mean retentate of the concentration step and (iii) the final mean retentate of the last diafiltration step. As already mentioned in this article, the toxin retention yields would be $\mathrm{pH}$ and ionic composition dependent (Alvarez et al. 2010). Thus, it should be noted that the $\mathrm{pH}$ of the raw solution containing the disrupted micro-algal cells (before any filtrations) was equal to 6.8. From a general point of view, the $\mathrm{pH}$ was ranged between 6.1 and 6.8 for ESP04-diafiltration, AFC30-concentration or AFC30-diafiltration. Unfortunately, the loss rates of toxins increased after each filtration step (Figure 3). If only the molar mass was considered, all toxins should freely pass through the ESP04 membrane since the molecular weight cut-off of the membrane was equal to $4 \mathrm{kDa}$. On the contrary, STX toxins which had the smallest molar masses (299 Da) were not the most recovered into the mean permeate of the first diafiltration. For reminder, the mean permeate refers to the entire permeate collected at the end of a filtration step. Moreover, $100 \%$ of $\mathrm{C} 2$ toxins passed through the ESP04 membrane whereas theirs molar masses were the highest (475 Da). Besides, the loss rates calculated after the first diafiltration were different between $\mathrm{C} 1$ and C2 or GTX2 and GTX3 whereas the molar masses were similar respectively. When sulfate was located on the third substituent group (C1 and GTX2 cases) the loss rates after ESP04-diafiltration seemed to be higher. The location of the charged functional groups could change the conformation, size or the surface properties of toxins. Thus, each toxin would interact differently with the membrane material. Adsorption on membrane surface, by hydrophobic interactions, could also reduce the transmission rates (Lee et al. 2008). Several toxins could also be entrapped into the dead volumes of the pilot plant or adsorbed on the pipe lines. Some toxins could also remain into the retentate side because of insufficient number of added diavolumes. Finally, as already found, PSTs could still be bounded to cell debris (GijsbertsenAbrahamse et al. 2006). Thus, these aggregates, may be larger than the pore size, would not pass freely through the membrane.

Toxins were lost again during AFC30-concentration and AFC30-diafiltration. Indeed, the toxin recovery rates were ranged from 55 to $94 \%$ during the last diafiltration step on AFC30 membrane (Table 3). Thus, all toxins were not recovered during these filtrations. Toxins with the smallest molar masses (STX) were the most lost. Toxins could be embedded on the membrane material again or into the pilot plant as well as passed through the nanofiltration membrane. 
In addition, the purification chain was implemented in order to remove a part of undesirable organic matter and salts. Table 4 shows the TOC and salt concentrations into the initial feedstock and final extract after complete purification process. At the end of all filtrations, $57 \%$ (mass/mass) of the total organic carbon (TOC) were removed while the conductivity was dropped by $78 \%$ (Table 4 ). The small and monovalent ions such as sodium $(83 \%)$ and chloride $(83 \%)$ were preferentially removed. On the contrary, $87 \%$ of sulphate, the biggest salt, remained into the final extract. Obviously, each salt could be associated with each other such as the sodium and chloride since the removal rates were similar (83\%).

As shown on tables 3 and 4, the loss of TOC and salts was often higher than that of toxins. Thus, there was a purification of the latter. For instance, $\mathrm{C} 1$ and $\mathrm{C} 2$ toxins were purified since $24 \%$ (average) were lost versus $57 \%$ of TOC while the conductivity decreased from $78 \%$. Nevertheless, STX toxins seemed to be partially purified since $73 \%$ of them were lost versus only $57 \%$ of TOC whereas the STX/salt ratio slightly increased. In all cases, no purification occurred respectively to sulphate ions which were poorly removed.

\subsection{Performance monitoring in the course of filtrations}

TOC concentrations were measured throughout filtrations (Figure 4). During the ESP04diafiltration, the TOC concentration of the retentate decreased from 121.5 to $10.3 \mathrm{mg} . \mathrm{L}^{-1}$. Unfortunately, a large amount of TOC (188.7 mg) was recovered into the mean permeate. This represented $79.8 \%$ of the amount initially found in the raw solution. Thus, the second step of purification began with a TOC concentration equal to $24.2 \mathrm{mg} . \mathrm{L}^{-1}$. The number of added diavolumes could be reduced in order to limit the TOC amount in the permeate provided that most toxins were able to pass through the membrane (see equation 1). On the contrary, a sufficient number of diavolumes has to be added in order to recover toxins into the permeate. Thus, the number of diavolumes will influence the degree of purification as well as the toxin amount of the mean ESP04 permeate.

The volume was reduced 4 times during the AFC30-concentration step. The organic transmission rates through the membrane were as low as 13.8 to $15.5 \%$ which induced a low but not null removal of organics during this concentration step.

Finally, a part of organic matter was still removed during the AFC30-diafiltration. As shown by the equation 1 , the concentration dropped following an exponential law. Thus, the final purified fitrate contained $53.7 \mathrm{mg} . \mathrm{L}^{-1}$ of TOC. As the $2^{\text {nd }}$ diafiltration proceeded, the TOC retention rates increased from 88.9 to $93.0 \%$. 
Salts passed almost freely through the ESP04 membrane since the conductivity of permeates and retentates were close to each other (Figure 5). Thus, during the ESP04-diafiltration, it decreased from 1170.4 to $64.6 \mu \mathrm{S} . \mathrm{cm}^{-1}$ following an exponential law. Consequently, the concentrations of each salt (sodium, magnesium, chloride, potassium, calcium, sulfate) were not much different into permeates and retentates (Figure 6). Thus, the evolution of salt concentrations in the course of ESP04-diafiltration was accurately modeled by assuming a transmission rate equal to $100 \%$ for all ions (Equation 1 - Figure 6). This result is not surprising considering the difference between pore size of the membrane $(4 \mathrm{kDa})$ and the molar masses of salts. Thus, this first diafiltration did not allow a significant removal of salts. For reminder, the TOC was also almost entirely recovered into the mean permeate of the ESP04-diafiltration. Thus, the addition of 4 diavolumes during this first diafiltration could appear unsuitable because not enough unwanted organic matter was retained while a part of toxins was lost. However, the kinetics of transmission through the ESP04 membrane were probably different between the undesirable TOC and toxins. The passage of the colloidal TOC could be more difficult than that of toxins. So, it could be interesting to stop the ESP04diafiltration as toxin concentration in the mean permeate would be almost constant. As a result, mean permeate would contain less undesirable organics and only slightly less toxins. The degree of purity of toxins would be improved. A more selective ultrafiltration membrane could also be found. The objectives would be to let pass the toxins while undesirable TOC would be more highly retained.

Comparatively to ESP04 membrane, the salt (conductivity) transmission rates were obviously smallest for the AFC30 one (Figure 5). They increased from 15.4 to $32.4 \%$ in the course of the concentration. Same trend (an increase) was observed for each ion except for the sulfate ions which were almost always entirely retained by the AFC30 membrane (Figure 7). Interestingly, during the AFC30-concentration, the retention rates of salts were almost always lower than those of toxins. Consequently, a pre-purification of toxins occurred. Thus, only 57 to $77 \%$ of salts (potassium, sodium, calcium, magnesium, chloride) remained in the retentate against 75 to $90 \%$ for toxins (C1, C2, GTX3, GTX2). Unfortunately, $94 \%$ of sulfate remained in the retentate and only $59 \%$ for STX toxins.

Finally, thanks to the last diafiltration, the conductivity was reduced by $66.3 \%$ (Figure 5). The retention rate of each salts slightly increased in the course of AFC30-diafiltration (Figure 8). However, a mean retention rate has been considered in order to model the evolution of the salt concentration during the final diafiltration. It was found a mean retention rate equal to $64.6,82.1,63.7,69.8,85.4$ and $99.0 \%$ for respectively sodium, magnesium, 
chloride, potassium, calcium and sulfate (Figure 8). Sulfate was almost always entirely retained contrary to sodium and chloride which passed the most freely through the AFC30 membrane. It should be noted that more diavolumes could be added during the final diafiltration step in order to enhance the purification yields. Indeed, more salts and undesirable organics would be removed. However, toxins must remain in the retentate.

\section{Conclusion}

The feasibility to pre-purify micro-alga's PST by a coupling membrane process was investigated. Encouraging results were obtained since several toxins have been successfully purified. It mostly concerns the $\mathrm{C} 1$ and $\mathrm{C} 2$ toxins. Nevertheless, STX toxins could be difficult to purify by membrane filtration. The degree of removal of undesirable organics could sometimes not be sufficient in order to obtain the toxin purification. Monovalent ions were rather well removed. Nevertheless, divalent ions seemed difficult to remove without toxin loss. Further work remains necessary for the optimization of the filtration process used. In fact, various membrane materials or molecular weight cut-off as well as operating conditions (transmembrane pressure, recirculating flow rate and temperature) could be tested in order to facilitate the toxin transmission through the ultrafiltration membrane, mitigate the membrane fouling, increase the selectivity, etc.

\section{Acknowledgments}

This study was carried out in the framework of Coselmar project supported by Ifremer and Nantes University and co-funded by the French Regional Council of the "Pays de la Loire".

\section{References}

Alvarez, M., Rose, J., Bellamy, B., 2010.Treating algal toxins using oxidation, adsorption, and membrane technologies. Denver, Colo.: Water Research Foundation, ISBN-10: 1605730823

Buarque, N. M. S., Buarque, H., Capelo-Neto J., 2015. Adsorption kinetics and diffusion of Saxitoxins on granular-activated carbon: influence of pore size distribution. J. Water Supply Research Technology-AQUA. 64, 344-353.

Camacho, F., Rodríguez, J., Mirón, A., García, M., Belarbi, E., Chisti, Y., Grima, E., 2007. Biotechnological significance of toxic marine dinoflagellates.Biotechnology Advances. 25, 176-194.

Cheryan M., 1986. Ultrafiltration Handbook. Technomic, Lancaster, PA 
Coral, L., Proença, L., De JesusBassetti, F., Lapolli, F., 2011. Nanofiltration membranes applied to the removal of saxitoxin and congeners.Desalination and Water Treatment. 27, 817.

Dixon, M. B., Falconet, C., Ho, L., Chow, C.W.K., O’Neill, B.K., Newcombe, G. 2011. Removal of cyanobacterial metabolites by nanofiltration from two treated waters.Journal of hazardous materials 188, 288-295.

Gallardo-Rodriguez, J., Sanchez-Miron, A., Garcia-Camacho F., Lopez-Rosales, L., Chisti, Y., Mollina-Grima, E., 2012.Bioactives from microalgaldinoflagellates.Biotechnology Advances. 30, 1673-1684.

Garrido, R., Lagos, N., Lagos, M., Rodríguez-Navarro, AJ., Garcia, C., Truan, D., Henriquez, A., 2007. Treatment of chronic anal fissure by gonyautoxin. Colorectal Dis. 9, 619-624

Gijsbertsen-Abrahamse, A.J., Schmidt, W., Chorus, I., Heijman, S.G.J.,2006. Removal of cyanotoxins by ultrafiltration and nanofiltration. Journal of Membrane Science 276, 252-259.

Guillard, R. R. L.and Hargraves, P. E. 1993.Stichochrysisimmobilis is a diatom, not a chrysophyte. Phycologia: 32, 234-236.

Haque, F., Banayan S., Yee, J., Chiang Y.W., 2017. Extraction and applications of cyanotoxins and other cyanobacterial secondary metabolites, Chemosphere, 183, 164-175.

Hejazi, M.A., Wijffels, R.H., 2004. Milking of microalgae. Trends in Biotechnology, 22, 189194.

Ho, L., Tanis-Plant, P., Kayal, N., Slyman, N., Newcombe, G., 2009. Optimising water treatment practices for the removalof Anabaena circinalis and its associated metabolites,geosmin and saxitoxins. Journal of Water and Health 7, 544-556.

Inoue, M., 2004.Convergent syntheses of polycyclic ethers.Illustrations of the utility of acetallinked intermediates. Org BiomolChem 2, 1811-1817.

Lattes, K., Venegas, P., Lagos, N., Lagos, M., Pedraza, L., Rodriguez-Navarro, AJ., Garcia, C., 2009. Local infiltration of gonyautoxin is safe and effective in treatment of chronic tension-type headache. Neurol. Res. 31, 228-233.

Laycock, M. V., Anderson, D. M., Naar, J., Goodman, A., Easy, D. J., Donovan, M. A., Li, A., Quilliam, M. A., Al Jamali, E., Alshihi R. 2012.Laboratory desalination experiments with some algal toxins. Desalination, 293, 1-6.

Lee, J., Walker, H.W. 2008.Mechanisms and factors influencing the removal of microcystinLR by ultrafiltration membranes. Journal of Membrane Science, 320, 240-247.

Merel, S., Walker, D., Chicana, R., Snyder, S., Baurès, E., Thomas, O., 2013.State of knowledge and concerns on cyanobacterial blooms and cyanotoxins, Environment International 59, 303-327. 
Oshima, Y., 1995. Postcolumnderivatization liquid chromatographic method for paralytic shellfish toxins.Journal of AOAC International. 78, 528-532.

Pyo, D., Oh, C., Choi J., 2004.Simultaneous Separation and Purificationof Microcystin LR, RR, YR by UsingSupercritical Fluid Extraction andColumn Chromatography, Analytical Letters 37, 2595-2608.

Rogers, R.S., and Rapoport, H., 1980, The pKa's of Saxitoxin, J. Am. Chem. SOC.,102, 7335-7339.

Rossini, G. P., 2014. Toxins and biologically active compounds from microalgae, Volume 1, Edit G. P. Rossini, CRC Press, Taylor and Francis group, A science publishers book, 542 Pages, ISBN 9781482210682.

Seubert, E., Trussell, S., Eagleton, J., Schnetzer, A., Cetinić, I.,Lauri, P., Jones, B., Caron, D., 2012. Algal toxins and reverse osmosis desalination operations: Laboratory bench testing and field monitoring of domoic acid, saxitoxin, brevetoxin and okadaic acid, Water Research 46, 6563-6573.

Teixeira, M. R. and Rosa, M. J. 2005.Microcystin removal by nanofiltration membranes, Sep. Purif. Technol. 46, 192-201.

Teixeira, M. R. and Rosa, M. J. 2006.Neurotoxic and hepatotoxic cyanotoxins removal by nanofiltration, Water Research 40, 2837-2846.

Vlad, S., Anderson, W. B., Peldszus, S., Huck, P.M., 2014.Removal of the cyanotoxinanatoxin-a by drinkingwater treatment processes: a review.Journal of Water and Health 12, 601-617.

Wang, D.Z., 2008. Neurotoxins from marine Dinoflagellates: a brief review, Marine Drugs 6, 349-371

Westrick, J., Szlag, D., Southwell, B., Sinclair,J., 2010.A review of cyanobacteria and cyanotoxins removal/inactivation in drinking water treatment.Anal.Bioanal. Chem. 397, 1705 1714.

Wiese, M., D'Agostino, P.M., Mihali, T.K., Moffitt, M.C., Neilan, B.A., 2010. Neurotoxic alkaloids: saxitoxin and its analogs.8,2185-211. 


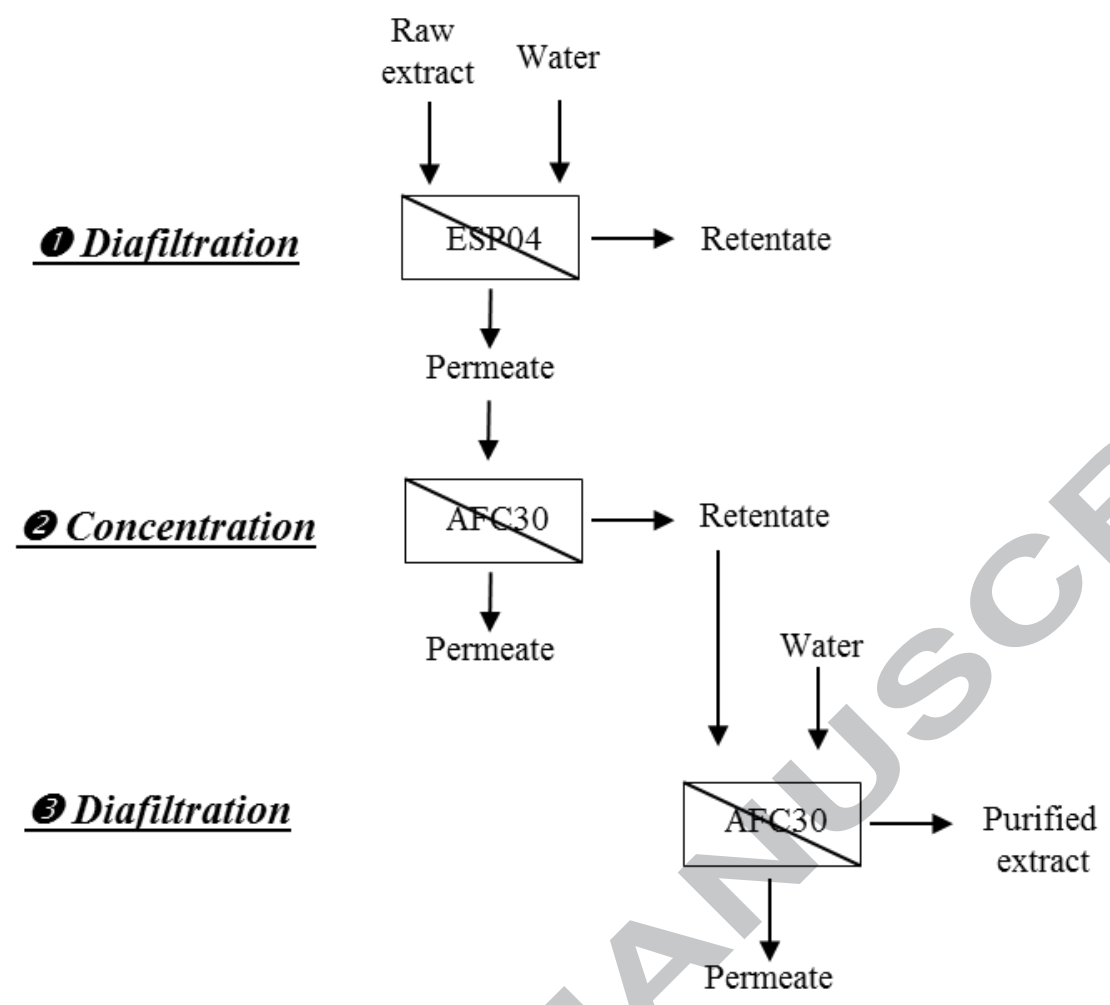

Figure 1: purification chain of toxin extract 


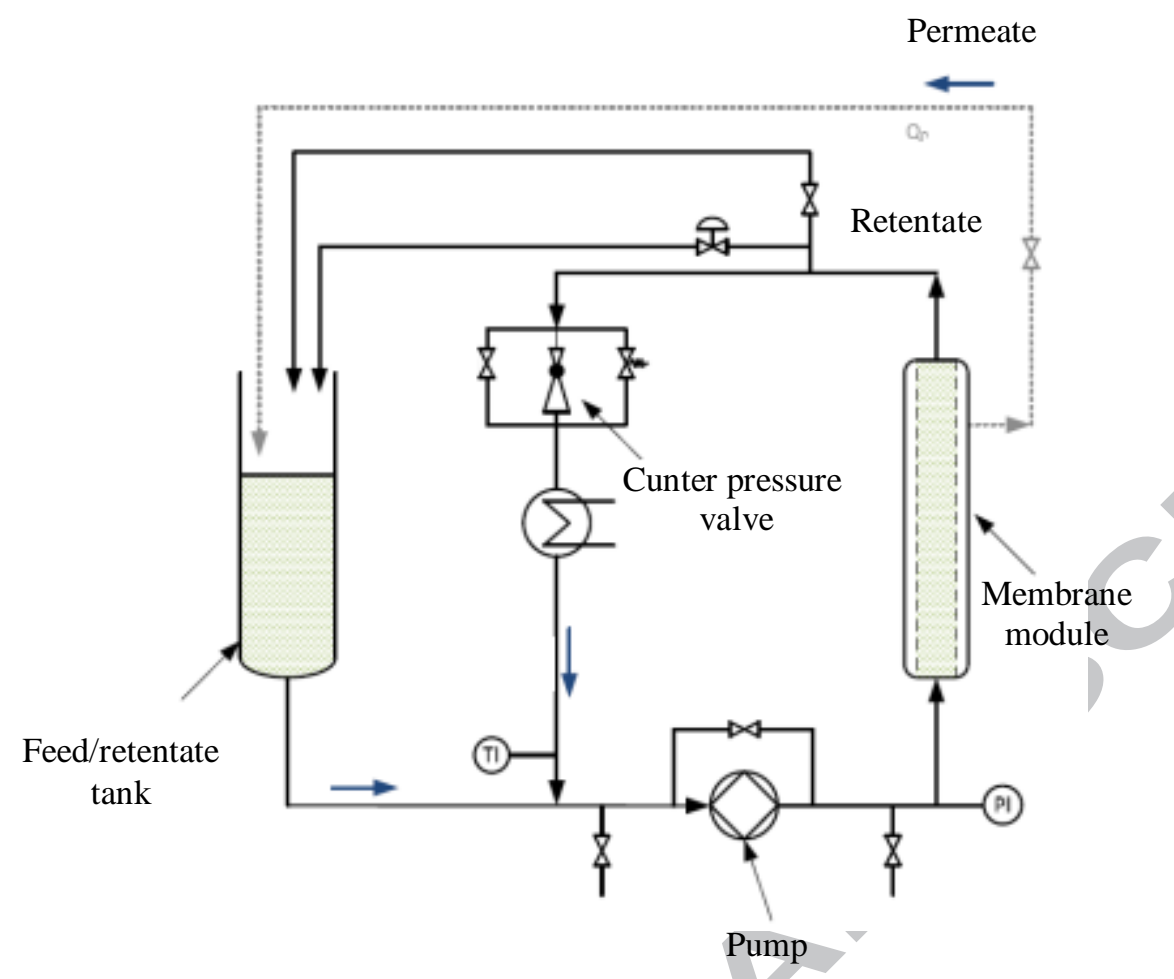

Figure 2: schematic diagram of the experimental setup 


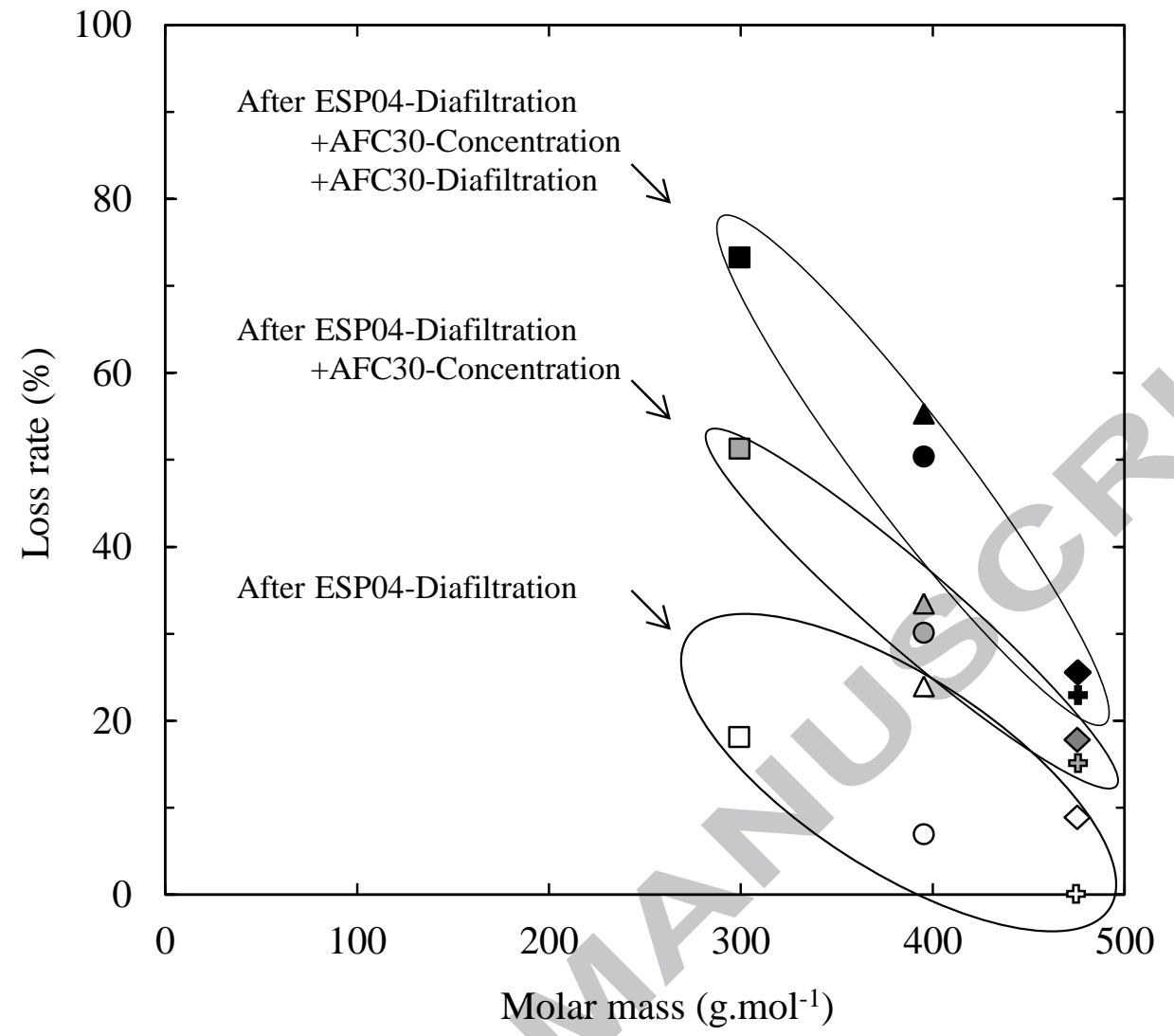

Figure 3: Global loss rates (molar basis) of STX (Squares), GTX2 (Triangles), GTX3 (Rounds), C1 (Diamonds), C2 (Crosses) toxins in function of theirs molar masses after: -ESP04-Diafiltration (white symbols)

-ESP04-Diafiltration then AFC30-Concentration (grey symbols)

-ESP04-Diafiltration then AFC30-Concentration then AFC30-Diafiltration (black symbols). For ESP04-diafiltration the loss corresponds to the percentage of toxins which are not recovered within the mean permeate. For AFC30-concentration and AFC30-diafiltration the loss corresponds to the percentage of toxins not recovered within the final concentrate. 


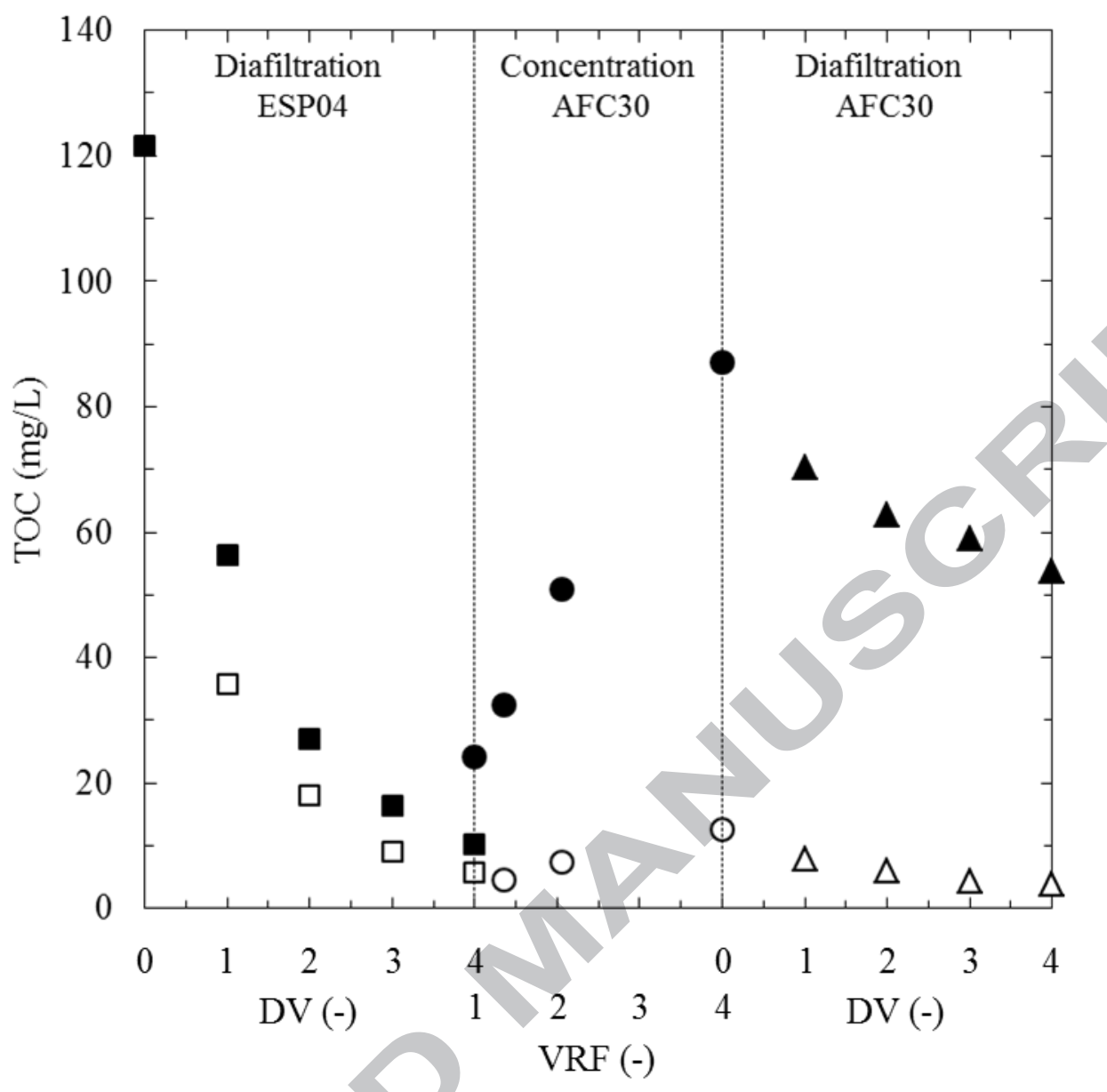

Figure 4: Evolution of TOC concentration during the ESP04-diafiltration (retentate ( $\mathbf{\square})$; permeate $(\square)$ ), the AFC30-concentration (retentate $(\bullet)$; permeate $(O)$ ) and the AFC30diafiltration steps (retentate $(\boldsymbol{\Delta})$; permeate $(\triangle)$ ). 


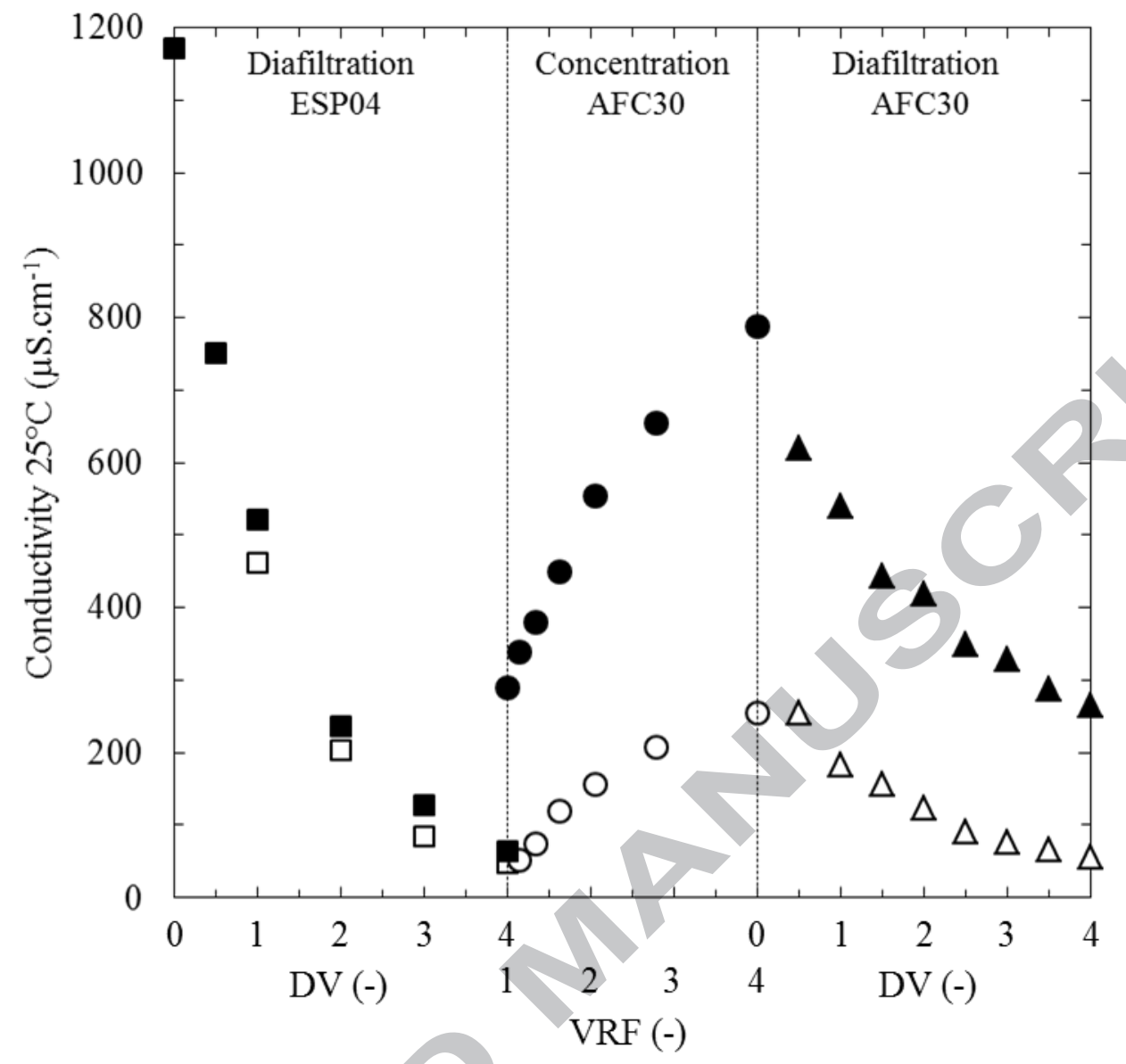

Figure 5: Evolution of the conductivity during the ESP04-diafiltration (retentate (ם); permeate $(\square)$ ), the AFC30-concentration (retentate $(\bullet)$; permeate $(O)$ ) and the AFC30diafiltration steps (retentate $(\boldsymbol{\Delta})$; permeate $(\triangle)$ ). 


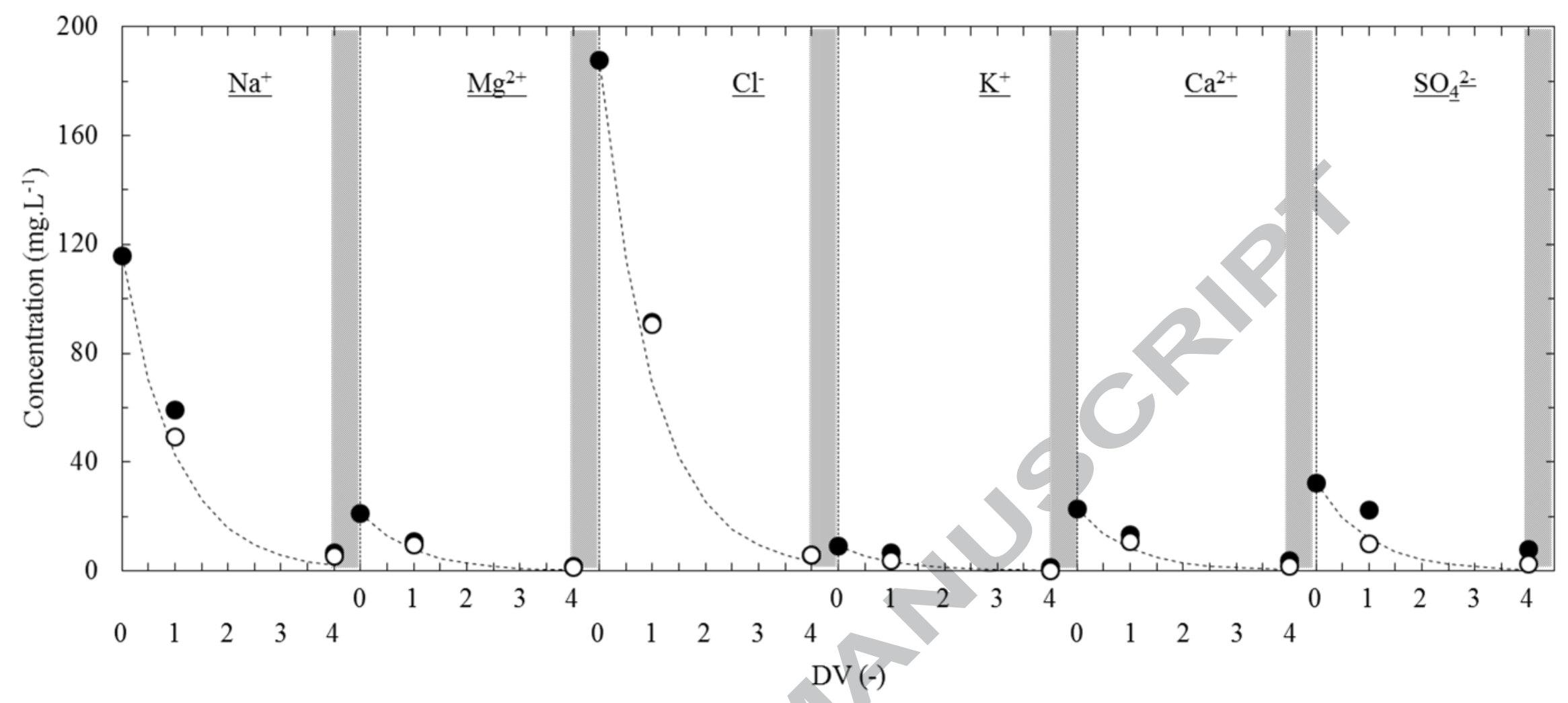

Figure 6: Change of concentrations of various ions into the retentates (experimental $(\bullet)$ and model (---) points) and permeates (०) during the ESP04 diafiltration step. A transmission rate of $100 \%$ was assumed for all ions in order to model from equation 1. 


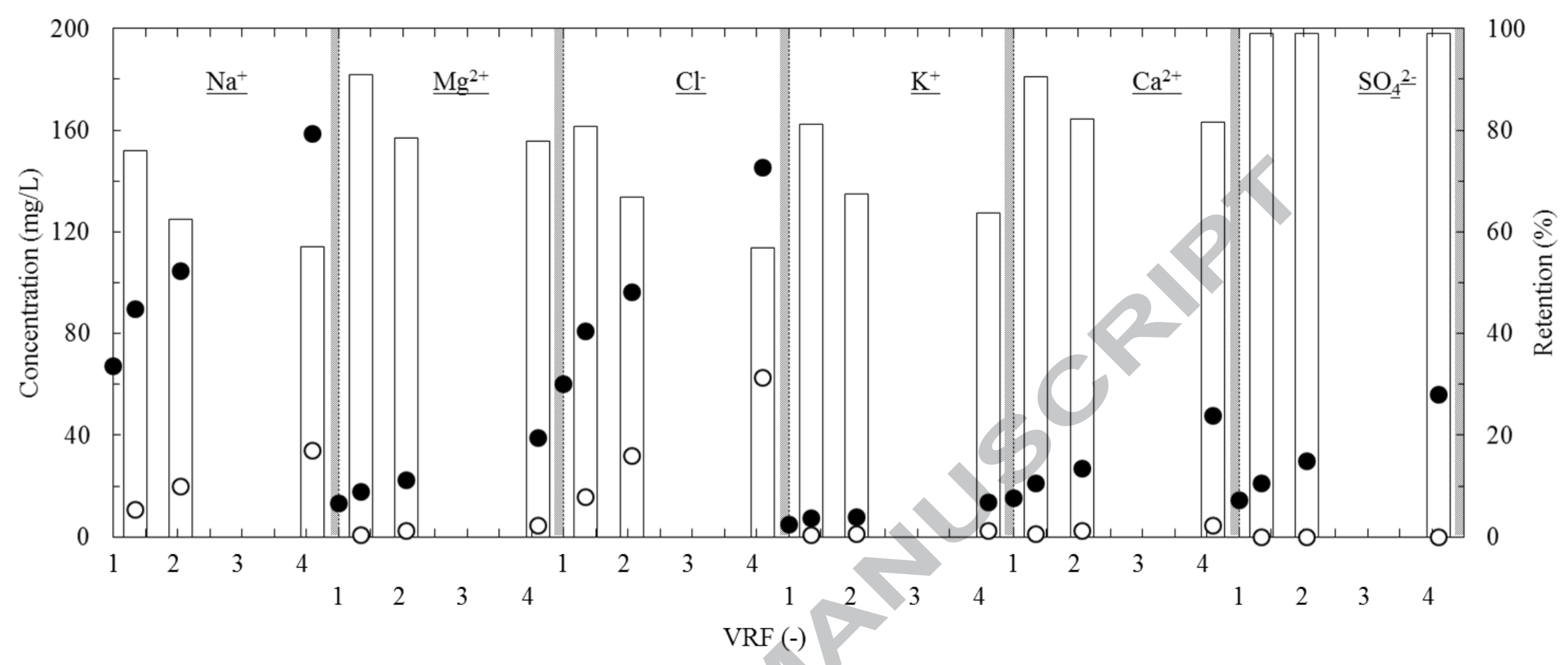

Figure 7: Change of concentrations of various ions into the retentates $(\bullet)$ and permeates $(\odot)$ and theirs retention rates $(\square)$ during the AFC30 concentration step. 


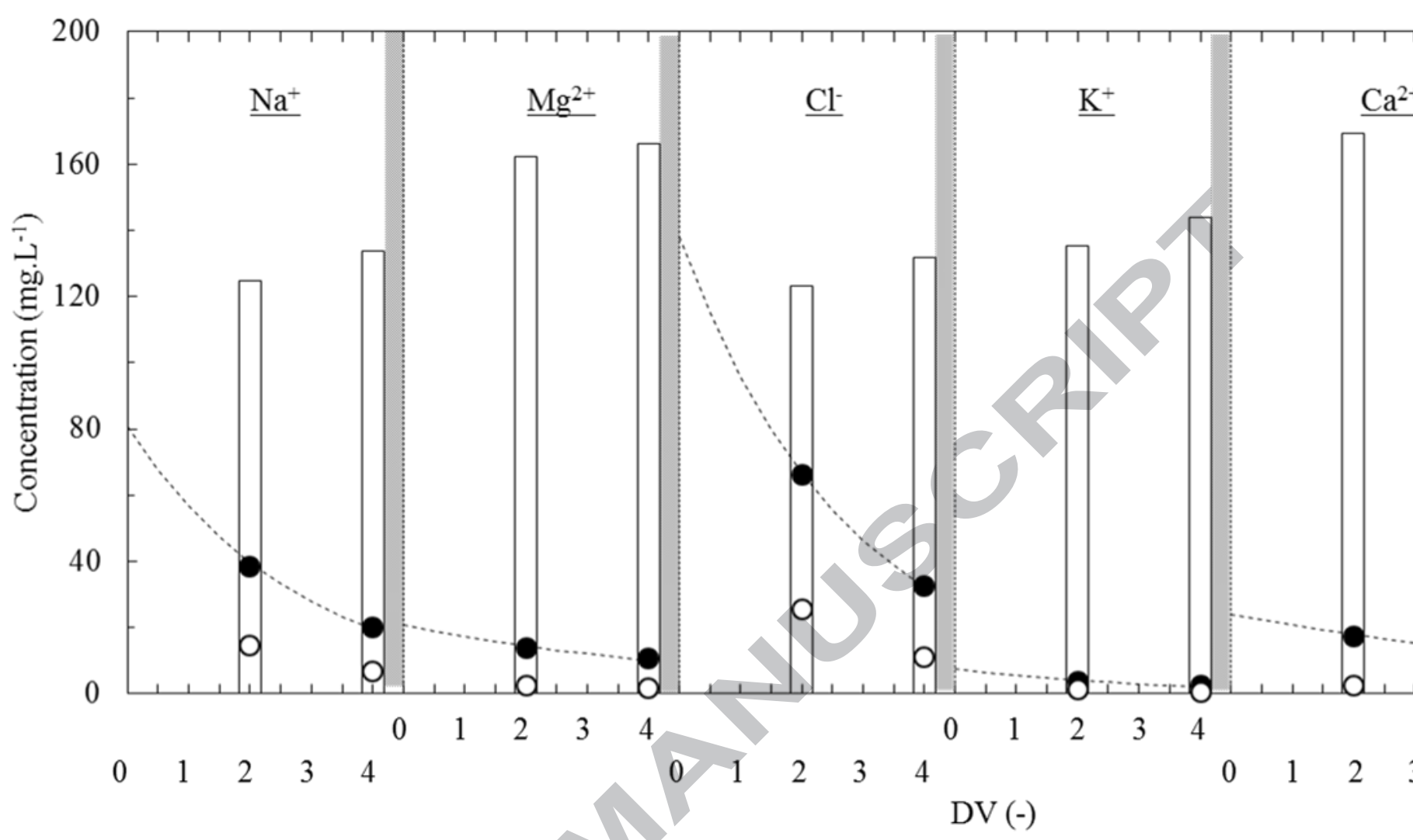

Figure 8: Change of concentrations of various ions into the retentates (experimental $(\bullet)$ and model (---) points) and permeates (०) and theirs retention rates ( $\square$ ) during the AFC30 diafiltration step. A mean retention rate of 64.6, 82.1, 63.7, 69.8, 85.4 and 99.0\% was taken for the model for respectively sodium, magnesium, chloride, potassium, calcium and sulfate ions. 
Table 1: structures of the main PST toxins

\begin{tabular}{cccc|c|c} 
Decarbamoyl \\
Toxins
\end{tabular}


Table 2: Characteristics of the membranes

\begin{tabular}{lll} 
& ESP04 & AFC30 \\
\hline Cut-off (Dalton) & 4000 & - \\
Nominal rejection rate & - & $75 \% \mathrm{CaCl}_{2}$ \\
Material & PES & PA \\
Maximum pressure (bar) & 30 & 60 \\
pH range & $1-14$ & $1.5-9.5$ \\
Maximum temperature $\left({ }^{\circ} \mathrm{C}\right)$ & 65 & 60 \\
Hydrophilicity & $2^{*}$ & $4 *$ \\
\hline PES: polyethersulfone; PA: polyacrylonitrile; &
\end{tabular}

*The rating was made on a five-point scale with 1 low and 5 high (manufacturer's data) 
ACCEPTED MANUSCRIPT

Table 3: material balance of the diafiltration and concentration steps

\begin{tabular}{|c|c|c|c|c|c|c|c|c|}
\hline \multirow{4}{*}{$\begin{array}{l}\text { Duration }(\mathrm{min}) \\
\text { DV or VRF } \\
\mathrm{J}_{\text {mean }}\left(\mathrm{L} \cdot \mathrm{h}^{-1} \cdot \mathrm{m}^{-2}\right)\end{array}$} & \multicolumn{3}{|c|}{ DIAFILTRATION ESP04 } & \multicolumn{2}{|c|}{ CONCENTRATION AFC30 } & \multicolumn{2}{|c|}{ DIAFILTRATION AFC30 } & \multirow{2}{*}{$\frac{\text { OVERALL }}{258}$} \\
\hline & & 75 & & & & 98 & & \\
\hline & & $7.8 / 1.9=4.1$ & & $7.8 / 1$ & & $7.8 / 1.9$ & & - \\
\hline & & 187 & & & & 135 & & - \\
\hline $\begin{array}{l}\text { Concentrations in } \\
\text { the various fractions }\end{array}$ & Feedstock & $\begin{array}{l}\text { Mean final } \\
\text { permeate }\end{array}$ & $Y_{P}(\%)$ & $\begin{array}{l}\text { Mean final } \\
\text { retentate }\end{array}$ & $\mathrm{Y}_{\mathrm{R}}(\%)$ & $\begin{array}{l}\text { Mean final } \\
\text { retentate }\end{array}$ & $\mathrm{Y}_{\mathrm{R}}(\%)$ & $\mathrm{Y}_{\mathrm{R}}(\%)$ \\
\hline $\mathrm{C} 1\left(\mu \mathrm{mol} . \mathrm{L}^{-1}\right)$ & 1.80 & 0.41 & 91 & 1.52 & 90 & 1.42 & 94 & 77 \\
\hline $\mathrm{C} 2\left(\mu \mathrm{mol} . \mathrm{L}^{-1}\right)$ & 1.05 & 0.28 & 107 & 0.91 & $81)$ & 0.80 & 88 & 75 \\
\hline GTX3 $\left(\mu\right.$ mol. $\left.L^{-1}\right)$ & 0.43 & 0.10 & 93 & 0.31 & 75 & 0.22 & 71 & 50 \\
\hline GTX2 $\left(\mu \mathrm{mol} . \mathrm{L}^{-1}\right)$ & 0.37 & 0.07 & 76 & 0.25 & 87 & 0.17 & 68 & 45 \\
\hline dc-GTX3 $\left(\mu \mathrm{mol} . \mathrm{L}^{-1}\right)$ & 0.01 & $\mathrm{Nd}$ & - & 0.02 & - & 0.02 & - & - \\
\hline dc-GTX2 $\left(\mu \mathrm{mol} . \mathrm{L}^{-1}\right)$ & 0.05 & $\mathrm{Nd}$ & - & 0.05 & - & $\mathrm{Nd}$ & - & - \\
\hline $\operatorname{STX}\left(\mu \mathrm{mol} . \mathrm{L}^{-1}\right)$ & 1.07 & 0.22 & 82 & 0.53 & 59 & 0.29 & 55 & 27 \\
\hline
\end{tabular}

$\mathrm{Y}_{\mathrm{P}, \mathrm{R}}:$ recovery rate into the mean permeate (ESP04) and retentate (AFC30) calculated from the final and initial concentrations and volumes of the given filtration step; ND : not detected; DV: number of diavolumes $\left(\mathrm{V}_{\mathrm{w}} / \mathrm{V}_{0}\right)$; VRF: final volume reduction factor. 
Table 4: Compositions of the feedstock and the final extract obtained after the complete purification as well as the global elimination rates

\begin{tabular}{ccc}
\hline & Feedstock & Final extract \\
\hline $\mathrm{pH}$ & 6.8 & 6.6 \\
$\mathrm{TOC}\left(\mathrm{mg} \cdot \mathrm{L}^{-1}\right)$ & 121.5 & 53.7 \\
Conductivity at $25^{\circ} \mathrm{C}\left(\mu \mathrm{S} . \mathrm{cm}^{-1}\right)$ & 1170 & 266 \\
$\mathrm{~K}^{+}\left(\mathrm{mg} \cdot \mathrm{L}^{-1}\right)$ & 9.2 & 2.5 \\
$\mathrm{Na}^{+}\left(\mathrm{mg} \cdot \mathrm{L}^{-1}\right)$ & 115.9 & 20.2 \\
$\mathrm{Ca}^{2+}\left(\mathrm{mg} \cdot \mathrm{L}^{-1}\right)$ & 22.8 & 13.8 \\
$\mathrm{Mg}^{2+}\left(\mathrm{mg} \cdot \mathrm{L}^{-1}\right)$ & 20.9 & 10.6 \\
$\mathrm{Cl}^{-}\left(\mathrm{mg} \cdot \mathrm{L}^{-1}\right)$ & 187.9 & 32.5 \\
$\mathrm{SO}_{4}{ }^{2-}\left(\mathrm{mg} . \mathrm{L}^{-1}\right)$ & 32.2 & 28.5
\end{tabular}

$\tau$ : elimination rate calculated from the final and initial mass concentrations and volumes as $1-\mathrm{C}_{\text {final }} \cdot \mathrm{V}_{\text {final }} /\left(\mathrm{C}_{0} \cdot \mathrm{V}_{0}\right)$ 